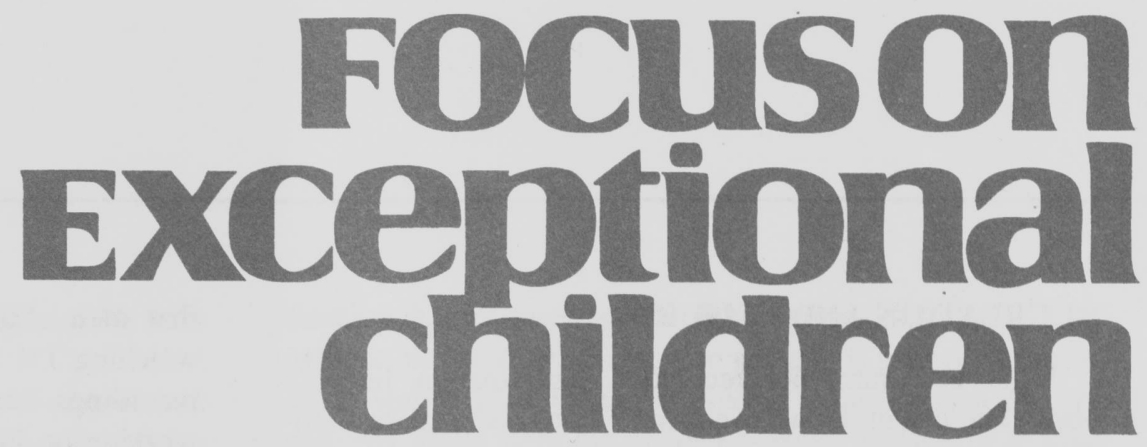

\title{
Transition for Children with Down Syndrome from School to Community
}

\author{
John E. Rynders, Stuart J. Schleien, and Shannon L. Matson
}

This article is an outgrowth of an early intervention study called Project EDGE (Expanding Developmental Growth through Education) at the University of Minnesota. The project provided family-based early intervention designed to improve the language skills of children with Down syndrome and whole family development. It turned out to be a longitudinal study from birth to adulthood. The purpose of this article is to provide some accurate, practical, research-based, cutting-edge information for parents and professionals dealing with recreation and leisure.

As a student with Down syndrome approaches high school graduation day, the family shifts its attention from school-based concerns to community-based concerns. This "one foot in school, one foot in the community" phase often is referred to as transitioning, an event or defined period during which substantial change is occurring (or should occur) in the lives of the individual with Down syndrome and his or her parents and siblings. An example of a transitioning period is the year of halfway house training that precedes the day when a young adult with Down syndrome moves out of the family home into an apartment in a semi-independent living setting. The transitioning event is the day the person actually moves.

The transitioning period leading up to graduation is a major one for the individual and his or her family. As graduation approaches, parents become anxious because of the unpredictability of the post-school period. Adding to parents' general anxiety is their uncertainty about whether the school has prepared their child to hold a job, make good use of free time, invite and maintain friendships, and live as independently as possible outside the parental home. Then, too, they wonder if the school has prepared their child sufficiently in socialization and literacy. On top of all this, they worry about their child's health and physical well-being.

John E. Rynders was with the University of Minnesota at the time this article was written. Shannon Matson was a graduate student in special education and early intervention at the University of Minnesota and is now with the residential and vocational services programs at the Courage Center Rehabilitation facility in Golden Valley, Minnesota. Stuart Schleien is with the Department of Recreation, Parks, and Tourism at the University of North Carolina in Greensboro. This article was adapted from Down Syndrome: Birth to Adulthood published by Love Publishing Company. 


\section{RECREATION AND LEISURE}

What is community recreation participation like for young adults with Down syndrome? Is it good, bad, or indifferent? A study of the community recreation/leisure pursuits of young men and women with Down syndrome, as reported by their parents, revealed that the most frequent activities took place in the family home and consisted mainly of watching TV, listening to music, playing alone with toys or games, and spending time with family members (Putnam, Pueschel, and Gorder-Holman, 1988). The most common community activities were religious activities, shopping, and going to movies, concerts, or plays. Other researchers and recreation professionals also have noted a "shallowness" in the depth and breadth of the lifestyles of people with developmental disabilities (Hayden, Lakin, Hill, Bruininks, \& Copher, 1992; Schleien and Werder, 1985). They found a lack of participation in a variety of community recreation activities, such as outdoor recreation and clubs, that are typical of their nondisabled peers.

Our survey of EDGE parents, whose sons or daughters with Down syndrome averaged 21 years of age, indicated

\section{Focuson
Exceptional
children}

ISSN 0015-511X FOCUS ON EXCEPTIONAL CHILDREN (USPS 203-360) is published monthly except June, July, and August as a service to teachers, special educators, curriculum specialists, administrators, and those concerned with the special education of exceptional children. This publication is annotated and indexed by the ERIC Clearinghouse on Handicapped and Gifted Children for publication in the monthly Current Index to Journals in Education (CIJE) and the quarterly index, Exceptional Children Education Resources (ECER). The full text of Focus on Exceptional Children is also available in the electronic versions of the Education Index. It is also available in microfilm from Xerox University Microfilms, Ann Arbor, MI. Subscription rates: individual, \$36 per year; institutions, \$48 per year. Copyright (C) 2003, Love Publishing Company. All rights reserved. Reproduction in whole or part without written permission is prohibited. Printed in the United States of America. Periodical postage is paid at Denver, Colorado. POSTMASTER: Send address changes to:

$$
\begin{gathered}
\text { Love Publishing Company } \\
\text { Executive and Editorial Office } \\
\text { P.O. Box } 22353 \\
\text { Denver, Colorado } 80222 \\
\text { Telephone (303) 221-7333 }
\end{gathered}
$$

Edwin Ellis

University of Alabama
Tim Lewis University of Missouri

Chriss-Walther Thomas University of Kansas

Susan T. Warhover Editor
Stanley F. Love Publisher that their children's most popular activity at home was watching TV, followed by listening to the radio or to tape recordings. The third most popular home-based activity was working on hobbies. Outside the home, the most popular activity was participation in sports, followed by shopping (for food, hobby materials, and the like) and visiting friends or relatives (though some of this visiting was in the home).

These results can be misleading because some recreation activities simply do not occur often enough to outstrip, at least in time-per-day, even fairly modest watching of TV, which is accessible $100 \%$ of the time, day or night. For instance, bowling in a league once a week for 2 hours could be an individual's favorite pursuit, but watching TV for just 30 minutes a day would show up on the survey as the most popular activity time-wise. Results also may be misjudged in that TV watching undoubtedly would show up as the favorite activity on a time-expended basis for many adults without disabilities as well.

Nevertheless, if we combine the categories of TV watching and listening to the radio and recordings and total the number of hours per week accumulated across the 15 EDGE young adults, participation in these passive activities averages approximately 5 hours per day, 7 days per week, for each individual. Spending this amount of time in a physically inactive pursuit has to be a contributing factor in the obesity that is characteristic of many adults with Down syndrome.

EDGE parents, however, did report that participation in sports, not as spectators, is their daughter's or son's third most popular recreation pursuit. Thus, these individuals probably have a substantial capacity for increasing active participation if we can facilitate it somehow. Participation in recreation of an active sort often is dictated as much (sometimes more) by the supports the community provides as by the individual's interests and aptitude. What can be done, therefore, to make community recreation program supports more bountiful and available? And what can be done to cultivate the recreation interests and aptitudes of individuals with Down syndrome and their family members?

\section{SIX STRATEGIES TO PROMOTE PARTICIPATION IN RECREATION}

In the last 10 years we have identified six strategies that make a significant difference in getting people with disabilities, including those with Down syndrome, out of the house, or at least out of their chairs. Not all of the strategies produce weight loss or significant improvements in physical fitness automatically, but at least they require more expenditure of energy than TV watching or radio and tape listening. More importantly, the recreational activity promoted through these strategies sometimes has been the key to 
advancing the personal development of young adults with Down syndrome.

In beginning to discuss strategies, parents should not assume personal, long-term, sole responsibility for implementing them. That's too exhausting for anyone! Besides, if parents continue to implement these strategies themselves, community and school personnel may not ever feel a need or responsibility to provide them. When the parent moves away (or becomes exhausted from the effort), the strategy will cease because no one in the community has learned it or is committed to implementing it. This "disappearing act" is all too common. Thus, parents might want to begin to use a strategy to demonstrate its effect, but they then should pass it on to a community professional.

\section{Strategy \#1: Assess the individual's recreation preferences.}

This sounds so "commonsensical" that it doesn't seem worth discussing. Still, it is because it signals to the individual with Down syndrome that his or her preferences are important. The person making the choice is ascribed importance, not a small matter for young adults with Down syndrome. Expressing a preference also has practical importance. Predicting young adults' preferences isn't always easy, as they may change during the transitioning period. Because young adults often are capable of advocating for themselves to some extent-with the attendant motivational benefit-this becomes even more important.

\section{Strategy \#2: Figure out how to get the preferred activity offered in the community in the most convenient way possi- ble by designing a step-by-step working plan.}

Here is where the technical sounding term task analysis comes in. Don't be put off by the sound of it. It's not difficult to understand or use, and it can be a powerful tool. It means that a task or activity is broken down into small steps that are observable and teachable. A comprehensive and detailed instructional plan that virtually any adult can use emerges. The parent then is able to suggest to a recreation provider, "I'd like my daughter to play miniature golf at your course" and also say, "Here's a plan that shows how my daughter can learn to play miniature golf at your facility if instruction is offered on an individual, step-by-step basis."

Let's look at a task analysis for Rose, a young adult with Down syndrome, as adapted from one we developed (Rynders \& Schleien, 1991). Rose's recreation preferences were assessed by showing her pictures of young adults participating in various age-appropriate activities such as swimming and playing softball. The pictures were presented in pairs representing all possible combinations. The picture of an adult using a Polaroid ${ }^{\mathrm{TM}}$ camera came up as her number-one choice, time after time. Therefore, Rose's father began to develop a task analysis for using a One-Step Polaroid ${ }^{\mathrm{TM}}$ camera, a camera that is easy to use and is user-friendly. He made sure that socialization aspects were embedded in the analysis along with the needed camera skills. (After Rose masters this relatively easy photography task, her father will add components to it that also involve adult literacy learning skills - for example, developing a task analysis for Rose's walking to the neighborhood store independently, purchasing film, returning home, and loading the film into the camera.) Here is Rose's task analysis for taking a picture of a companion (Rynders \& Schleien, 1991).

1. Ask the companion, "May I take a picture of you?"

2. If the reply is "yes," point to or suggest where person should sit or stand (not more than 12 feet away), with the sun shining on the person's face, but not directly in his or her eyes.

3. Ask the person to smile.

4. Grasp opposite sides of the camera with both hands, the lens facing away from body and toward the person/subject.

5. Raise the camera until you can see through viewfinder.

6. Center the person/subject in viewfinder.

7. Position your index finger directly in front of the shutter release button.

8. Push the shutter release button until it is depressed completely.

9. Wait for the photograph to emerge from the camera.

10. Remove the photograph from the camera.

11. Hold the photograph face up in your palm until it develops fully.

12. Show the photograph to others, then place it in a photo album.

After a task analysis has been completed, it is not only a helpful planning tool, but it also becomes a useful tool for keeping track of (evaluating) progress in the recreation activity and for revealing exactly where instruction is needed. To show how this is so, let's imagine that Rose is not able to perform step 11 of the task analysis (hold photograph until it develops) very well. How does this become evident? Rose's father gave her three chances to take a photo of a companion independently without any instruction, and he put an X in front of each step that Rose didn't do or did inadequately. Thus, he had a written record (three noninstructed attempts to perform the task on her own), which showed that Rose dropped the developing photograph all three times onto the ground after it emerged from the camera. She did not hold onto it and did not wait for it to develop fully.

Having recorded Rose's uninstructed capabilities, her father gave her specific instruction in this step by itself. He 
demonstrated how the film looks when it's fully developed by taking five photos himself so she could observe how to hold the photograph and wait for it to develop completely. Then, to help her get past this step, he instructed her to count to 60 before touching the front of the photo and then to remove it over a table (Rose can count to 100 easily and accurately).

Each time Rose does this step correctly, he says something pleasant to her such as, "Wow, Rose, look how good that photo looks!" When she does it incorrectly he says something like, "Whoops, you need to count to 60 before you touch the front of the photo, Rose." Then he asks for the camera and he instructs her again. After Rose has mastered this step, it is put back into the context of the whole photography task analysis and she will be given an opportunity to do all of the steps on her own again. If she muffs the step she practiced (or any other step), her father will instruct her in that step until she finally is able to do all the steps correctly and independently, several times in a row.

\section{Strategy \#3: Learn how to adapt a task so that its difficult parts can be avoided or overcome (Schleien, 1981).}

\section{Material Adaptations}

Materials and equipment used in an activity can be barriers to participation because they've been designed by and for individuals without disabilities. These may be adapted, however.

For example, equipment may be modified to permit bowling by individuals with Down syndrome, who often have limitations in fine and gross motor coordination, balance, and muscular strength required to lift and launch a bowling ball down an alley with reasonable skill. In some circumstances the bowling ball may be placed on top of a tubular steel bowling ramp. The bowler then aims the ramp at the pins and releases the ball. A bowling ball pusher, similar to a shuffleboard stick, also may be used to push the ball down the alley. The pusher may be adjusted to various lengths, allowing ambulatory and nonambulatory, short and tall, individuals to bowl. A third adapted bowling device that can be used by a person who is not able to lift and launch a conventional ball is a handle-grip bowling ball. A simple grasp of the handle in the palm of the hand and basic grossmotor arm movements are required to manipulate this adapted device. Once released, the handle snaps back, flush, into the bowling ball, allowing the ball to roll down the alley toward the pins. These three adaptations can permit a greater number of individuals with Down syndrome to enjoy the game of bowling.

Some types of adapted equipment are available commercially and can be purchased from sporting goods and hobby stores, specialty shops, and mail-order houses. Many adapted recreational materials and equipment can be devised by an activity leader (e.g., therapeutic recreation specialist) or a parent. For instance, a tennis racket handle may be enlarged using sponge or foam rubber and then wrapped with masking tape to allow for easier grasping and control of the racket.

A simple adaptation that can make a camera easier to use is to extend the shutter release button by attaching a piece of a crayon or other extension. This makes the button easier to locate and press.

\section{Procedural and Rule Adaptations}

If an individual's physical, intellectual, or social limitation makes a rule difficult to follow, it may result in a potential active participant becoming a passive spectator. Rules may be modified or simplified to make participation possible. They also may be altered when teaching a game, and later rewritten to approximate the rules that nondisabled peers follow. For example, basketball requires a player to bounce or dribble the ball every time a step is taken down the court. A change that permits one dribble for several steps down the court may permit an individual with difficulty in eye-hand-foot coordination to become an active and successful member of the team. Or the individual could learn to bounce and catch the ball instead of using the more difficult, standard dribble. With practice, coordination may improve and the regular rules can be used.

The rules in card games also may be modified. For example, the game "Concentration" requires players to draw two cards consecutively, with the object of drawing the most matched pairs. To make it easier to discriminate between number and picture cards, all picture cards (such as jacks, queens, kings) could be assigned the same value. Another modification of the game would be to use paired photographs of the player and each of his or her friends and family members to create a modified deck of playing cards. This not only simplifies the game but also can make it more motivating and enjoyable.

\section{Skill Sequence Adaptations}

Sometimes a sequence of steps applicable to a nondisabled individual may be too difficult or impractical for a person with Down syndrome. A hobby such as cooking provides a clear illustration of this. When boiling an egg, a nondisabled person might place the egg into a saucepan of boiling water. This could be hazardous (a scalded hand) to an individual with physical or intellectual limitations. To remedy this problem, the sequence of the component steps of the skill could be rearranged. The participant could place the egg into the saucepan, then fill the saucepan with cold water, then place the saucepan onto the stovetop burner and bring the water to a boil. This procedure does not alter the 
final results (of boiling an egg and making egg salad). It does add several minutes to the cooking time, but it is a safe and practical method of performing this enjoyable task. As another adaptation, a long-handled, slotted spoon could be used to place the egg in and remove it from the boiling water.

A modified skill sequence also is applicable to manipulating a camera. Typically, a photographer first raises the camera to eye level and then places his or her index finger on the shutter release button. An individual lacking finemotor coordination could be trained to position his or her finger on the shutter release button before lifting the camera to eye level. In this way, he or she merely has to depress the button once the camera is positioned appropriately.

\section{Facility Adaptations}

The local swimming pool, museum, restaurant, video arcade, library, church or synagogue - all should be accessible to people with Down syndrome. Unfortunately, some individuals have limited access to these places because of narrow doorways, inadequate toileting facilities, and imposing staircases. In addition, transportation to many sites is inadequate. These architectural barriers are being overcome gradually by the installation of wheelchair ramps leading into buildings, enlarged doorknobs, extended handles on drinking fountains, and other adaptations that promote full use by all individuals. Modifications should blend in with standard equipment whenever possible so nobody will stand out as being too different from peers.

For example, the following could make pier fishing accessible to a person with Down syndrome who has physical disabilities requiring the use of a wheelchair:

- An access walk to the pier at least 5 feet wide to allow for turning of a wheelchair.

- A handrail around the entire pier 36 inches high with a sloping top at a 30-degree angle for resting the arm and pole.

- A kick-plate to prevent foot pedals of wheelchair from falling off the pier.

- A smooth, nonslip surface on the access walk and the pier.

\section{Lead-Up Activity Adaptations}

A lead-up activity is a simplified version of a traditional activity or an exercise that allows practice in some component skill. Several lead-up activities may be chained together to teach specific skills necessary to engage in a more complex activity successfully. For example, a player can learn many of the skills involved in volleyball by participating in the game of "Newcomb," which requires participants to catch and throw a ball over a net. The concepts of returning the ball over the net, scoring team points, and rotating players can all be learned during the adapted version. An additional lead-up activity may be necessary to develop the skills needed for tapping the ball over the net. This can be done by having the players form a circle while taking turns tapping the ball to a player in the center of the circle.

By learning a more complex activity in small steps, full participation can be shaped and possibly accomplished eventually. Some individuals with Down syndrome may not be capable of mastering all the skills required to participate in the original activity. In this case, the lead-up activity itself may become a rewarding experience.

These five types of adaptations are the primary ways in which a creative program leader can reduce failure and frustration for all participants. In developing adaptations, activity leaders, parents, and the participants themselves must discuss barriers and adaptations. Many of the most creative and effective ideas come from these discussions.

Let's take a moment to see how adaptation strategies are helpful to Sally, a young adult with Down syndrome who doesn't read well or speak clearly. Sally's favorite leisure activity is to go to McDonald's. She usually is able to order what she wants because the task of ordering food has been adapted for her. She uses small cards, each picturing an item from the menu along with the term corresponding to the picture. Sally recognizes the picture but doesn't read the words well; the cashier doesn't need to look at the picture but knows what Sally wants by reading the words on the cards. This adaptation makes this recreation activity accessible to Sally.

Strategy \#4: Put together a focus group along with a circle of friends.

A focus group is composed of people who have a common interest-in this case, an interest in turning the recreational preferences of a young adult with Down syndrome into recreational opportunities. (A focus group also can concentrate on the individual's vocational and independent living preferences while attending to the recreation area because all three areas of community life are interrelated.) The focus group consists of several people who have a stake in the young adult's achieving a goal. The group also may include other adults who are likely to make things happen to reach the goal. To this focus group can be added a small circle of friends, two or three people (with or without Down syndrome or another disability) who volunteer to become cooperative partners, teammates, or tutors during the recreation activity.

Together, members of the focus group, with the circle of friends added to it, think aloud (with the young adult with Down syndrome's direct involvement, if possible) about 
how to fully use a recreation program that is of prime interest to the person with Down syndrome. After making certain that everyone is comfortable and has been introduced to every member of the group, the facilitator focuses the group on the following points:

1. What does the individual with Down syndrome want to do? Where can she or he do it?

2. What barriers exist to her or his achieving the desired goal or goals?

3. How can we, as a focus group, break down these barriers?

4. Who will do what?

5. How can we check for progress?

An important function of a focus group is to identify adults who will either agree to take on facilitation roles themselves or agree to take responsibility for finding others who are willing to take on these roles.

\section{Strategy \#5: Adult facilitation of recreational involvement.}

From the focus group process, at least two adult facilitators should emerge. Of the two, one should take on "coaching" responsibilities - to encourage social interactions and skill development during the recreation activity. This dual emphasis is recommended because recreation activities usually contain both socialization and task skill elements. For example, doing well at a picnic involves using good manners (skill) and engaging in appropriate light conversation (social). Playing bocce (a mix between lawn bowling and horseshoes) involves learning how to toss the ball properly and follow the rules of the game (skill) and to wait patiently to take a turn (social). Riding a public bus requires the ability to recognize the type and number of coins needed for the fare (skill) and, while seated, to not talk loudly or indiscriminately (social).

The coach can develop a task analysis that blends skill and socialization concerns, ensuring that social interactions prosper and task skill inadequacies that are getting in the way of fruitful social interactions are "sidecoached." The person may be removed only temporarily from the group for specific task instruction and, as quickly as possible, placed back in the group again to practice what has been learned in the social context (unless the skill of concern happens to be a social skill that is developed best within the group itself).

This coach also should learn to play "What if?" with members of the recreation group and with the individual who has Down syndrome. For example, the coach says to the young adult with Down syndrome, "Suppose you've ordered a hamburger at McDonald's, paid for it, and taken it to your table. When you open the wrapper, you see you've been given a fish sandwich instead (you don't like fish).
What would you do? What would you say?" With nondisabled participants the coach says, "You're playing Newcomb (the adapted version of volleyball). The ball is thrown to Larry (who has Down syndrome), but Larry isn't paying attention and the ball hits him in the back and falls to the ground. Larry drops to the ground, beating on the ball with his fists and shouting angrily. What should you do when the person you are with has a childlike tantrum and is a young adult who has Down syndrome?"

The second facilitator that should emerge from the focus group process is an adult who concentrates on making more community recreation personnel, facilities, and programs accessible to young adults with Down syndrome. This facilitator helps connect people, places, and programs into a network of supportive elements. For example, the local YMCA offers an aerobics program that a young adult with Down syndrome who lives 2 miles away would enjoy very much, but arranging public transportation (such as Metro Mobility) for her has become time-consuming and complex. The second adult facilitator (a member of the focus group who is an aerobics teacher at the local YMCA) phones members of the aerobics class until she finds four people who will take turns picking up and returning the person with Down syndrome for the once-per-week class.

\section{Strategy \#6: Promote adult functional literacy as needed.}

It may seem odd to include this topic in an article concerning recreation and leisure for young adults, but for some young adults with Down syndrome, reading is an important leisure activity in its own right. Functional literacy enables others to participate in preferred recreation and leisure activities. For example, knowing how to set a timer and turn a dial to a specified temperature allows Jennifer to bake a frozen pizza in her oven (pizza is her favorite recreational food). Knowing how to read the names of two streets and to count the four blocks between their intersection and his place of work enables Paul to catch the bus that stops on the corner of Vermont and Second, which gets him downtown to the movie theater, his favorite recreational site.

These are adult functional literacy skills, built on the academic learning of the earlier school years. Academic learning during schooling, however, may not have taken people with Down syndrome far enough to operate relatively independently in the areas of recreation and leisure (or the vocational and independent living areas either). Adult functional literacy has two interrelated aspects: (a) academic ability, and (b) capability of applying whatever academics have been learned to a practical context. The capability of counting by $5 \mathrm{~s}, 10 \mathrm{~s}$, and $25 \mathrm{~s}$ is an academic ability. Translating that ability into the speedy, accurate counting of nickels, dimes, and quarters to pay a bus fare is the applied capability. 
When a person with Down syndrome approaches the final years of schooling, the academic part of functional literacy - such as decoding new words and increasing reading vocabulary from a developmental standpoint-sometimes is abandoned in favor of mastering the sight recognition of whole words and phrases that are important to safety and basic needs-for example, learning to recognize "entrance," "exit," "men," "women," "danger," "do not enter," "bus stop," "wait." For the young adult with Down syndrome who is interested in and capable of further academic growth, however, we believe that abandoning academic training is not a good idea because of its relation to supporting adult functional literacy and community living in general. At the later stages of schooling, teachers and job coaches must concentrate on preparing the individual to function in the adult community where reading signs such as "exit" have to take priority, but to discontinue academics (for example, to stop instruction in phonics or to give up on counting proficiently by $1 \mathrm{~s}, 5 \mathrm{~s}$, and $10 \mathrm{~s}$ ) will mean a more restricted adult functional literacy repertoire.

In a way, we have created a dilemma for ourselves. Should we continue academic instruction far into the adult years, hoping that adult functional literacy eventually will improve substantially? Or should we cut off academic instruction, let's say at age 18 , substituting only crucial adult functional literacy learning experiences? The answer, in our opinion, relates to the young adult's ability level and motivation.

If at age 18, for example, the young adult is still growing in academics and still interested, why not continue this instruction in parallel with vocational, recreational, and independent living training? If, on the other hand, the individual is not good at academics at age 18 and is not interested in pursuing academics, why not shift to an emphasis on adult functional survival literacy skills such as teaching 150 sight words that are absolutely essential for health, safety, and successful participation in the community?

To argue convincingly that academics should not be abandoned for all young adults with Down syndrome, we must be able to demonstrate that some individuals with Down syndrome have good potential for continuing academic learning in the later years of schooling.

From the perspective of individual academic growth, the reading comprehension scores of some individuals were too low to be converted to a grade equivalent when they were about 12 years old, and this difficulty was still present when they were about 21 years old. For them, discontinuing developmental academics (such as learning to decode words through a phonic approach) seems warranted. On the other hand, some EDGE students read quite fluently. Academic instruction has paid off, giving them an important and versatile tool to use, not only functionally in the workplace and living environment, but in community recreation as well.
For them, continued developmental/remedial academic instruction, in combination with functional literacy requirements of a work or recreational setting, might be ideal.

\section{SPECIAL OLYMPICS}

We cannot close this article with its emphasis on recreation and leisure without discussing the Special Olympics (S.O.) program in the lives of EDGE children and their families.

For several years now the S.O. program has received "negative press" from some advocates of the full-inclusion movement. Although we would not want a self-contained version of S.O. to be the only outlet through which people with Down syndrome could enjoy competition, neither do we wish to see it eliminated. It has been one of the "mountaintop" experiences for athletes with Down syndrome in the EDGE project. Ideally we would like to see a broad array of recreational and sports programs for people who have Down syndrome or other disabilities, ranging from self-contained, such as traditional S.O., to fully integrated programming, such as the adventure programs of Wilderness Inquiry. People with Down syndrome then could have both options available to them and choose to participate in both if they wish. The importance of freedom of choice is illustrated in the findings of a recent study (Neumayer, Smith, \& Lundgren, 1993). In the study, 21 young adults with Down syndrome watched a videotape showing nondisabled young adults or young adults with Down syndrome participating in recreational bowling. Of the 21 viewers, 15 said that they would rather bowl with companions who also had Down syndrome.

An example of a young adult who participates in both a self-contained and an integrated recreation program is Rick, an EDGE participant. Rick belongs to a regular community health club that emphasizes bodybuilding. He is the only young adult in the club who has Down syndrome. Rick never has taken first place in open competition with nondisabled peers of his age, but he has taken third place in open competition. That's an incredible accomplishment, one that is not only a credit to him and to his family but also should help professionals who have limited expectations of people with Down syndrome raise their sights. Rick also participates in a self-contained S.O. program as a weight lifter, where he has won several medals.

Rick's participation in a regular health club bodybuilding program would appear to challenge the merit of a cooperative learning strategy for those with Down syndrome. Rick, after all, is competing with nondisabled peers, and not in the usual cooperative or individualistic framework. Cooperative, competitive, and individualistic strategies are all legitimate as long as they fit the person's and his or her peers' 
needs. Rick is one of a relatively few individuals with Down syndrome who has developed his body well enough to compete head-to-head with nondisabled peers. Moreover, his nondisabled peers support his athletic development because the coach has created a cooperative atmosphere within the club, an example of how cooperation can be built into competition.

\section{NONTRADITIONAL COMMUNITY RECREATION/LEISURE OUTLETS}

When young adults leave school altogether, finding satisfying recreational and leisure outlets in the community often becomes more difficult. The movie theater still exists as it did during the school years, but organized, ongoing activities, many of which are connected in some way with school, tend to diminish rapidly after graduation. Sometimes this void actually becomes the impetus for parents to find a place for the person with Down syndrome to live with other peers who have disabilities. A group home, among other possibilities, represents a built-in group of companions as well as an out-of-home living environment.

Here again is where a focus group can be extremely helpful in facilitating the participation of a young adult who has Down syndrome in recreation and leisure programs, depending on the individual's interests. Some ideas from EDGE parents and the recreation/leisure literature are as follows:

1. The neighborhood YMCA or Jewish Community Center may have integrated or segregated swimming, aerobics, ballet, or other young adult programs.

2. The local church or synagogue may have a social club, again integrated or segregated, combining socialization opportunities and religious education.
3. Park and recreation programs may offer integrated activities that accommodate young adults with disabilities. We know of an integrated bocce league for young adults that is doing quite well.

4. Of course, finding a young adult who has Down syndrome and interests similar to those of your young adult son or daughter with Down syndrome opens up dozens of opportunities to go for a walk, buy a hamburger at the local fast-food restaurant, attend a movie, go fishing, and do other things that friends enjoy together.

\section{REFERENCES}

Hayden, M., Lakin, K. C., Hill, B., Bruininks, R., and Copher, J., "Social and Leisure Integration of People with Mental Retardation in Foster Homes and Small Group Homes," Education and Training in Mental Retardation 27 (1992): 187199.

Neumayer, R., Smith, R., and Lundgren, H., "Leisure Related Peer Preference Choices of Individuals with Down Syndrome," Mental Retardation 31 (1993): 396-402.

Putnam, J., Pueschel, S., and Gorder-Holman, J., "Community Participation of Youths and Adults with Down Syndrome" (pp. 77-92), in S. M. Pueschel (ed.), The Young Person with Down Syndrome: Transition from Adolescence to Adulthood (Baltimore: Paul H. Brookes, 1988).

Rynders, J., and Schleien, S., Together Successfully: Creating Recreational and Educational Programs That Integrate People With and Without Disabilities (Arlington, TX: Association for Retarded Citizens of the United States, 1991).

Schleien, S., "Adapting Leisure Skills" (pp. 59-88), in P. Wehman and S. Schleien, Leisure Programs for Handicapped Persons: Adaptations, Techniques, and Curriculum (Austin, TX: Pro-Ed, 1981).

Schleien, S., and Werder, J., "Perceived Responsibilities of Special Recreation Services in Minnesota," Therapeutic Recreation Journal 19 (1985): 51-62. 